\title{
Influence of Au Plasmons and Their Synergistic Effects With ZnO Nanorods for Photoelectrochemical Water Splitting Applications
}

\section{Sayed Abdul Saboor}

Savitribai Phule Pune University

\section{Vidhika Sharma}

Savitribai Phule Pune University

Ebrima L. Darboe

Savitribai Phule Pune University

Vidya Doiphode

Savitribai Phule Pune University

\section{Ashvini Punde}

Savitribai Phule Pune University

\section{Pratibha Shinde}

Savitribai Phule Pune University

Vijaya Jadkar

Savitribai Phule Pune University

\section{Yogesh Hase}

Savitribai Phule Pune University

\section{Ashish Waghmare}

Savitribai Phule Pune University

Mohit Prasad

Savitribai Phule Pune University

Sandesh R. Jadkar ( $\nabla$ sandesh@physics.unipune.ac.in )

Savitribai Phule Pune University https://orcid.org/0000-0002-0610-7242

\section{Research Article}

Keywords: Photo-current, Plasmons, Photoelectrochemical, Zinc oxide

Posted Date: March 2nd, 2021

DOI: https://doi.org/10.21203/rs.3.rs-239798/v1 
License: (c) (i) This work is licensed under a Creative Commons Attribution 4.0 International License. Read Full License

Version of Record: A version of this preprint was published at Journal of Materials Science: Materials in Electronics on July 22nd, 2021. See the published version at https://doi.org/10.1007/s10854-021-065644. 
Influence of Au plasmons and their synergistic effects with ZnO nanorods for photoelectrochemical water splitting applications

Sayed Abdul Saboor, Vidhika Sharma, Ebrima L. Darboe, Vidya Doiphode, Ashvini Punde, Pratibha Shinde, Vijaya Jadkar, Yogesh Hase, Ashish Waghmare, Mohit Prasad ${ }^{\star}$ School of Energy Studies, Savitribai Phule Pune University, Pune 411007 (India) Sandesh Jadkar* Department of Physics, Savitribai Phule Pune University, Pune 411007 (India)

\title{
${ }^{\star}$ Corresponding authors
}

E-mail: sandesh@physics.unipune.ac.in (Sandesh Jadkar) mohitprasad7@gmail.com (Mohit Prasad)

\author{
Tele/Fax: + 9102025692678 \\ Tele/Fax: + 9102025692678
}

\begin{abstract}
In this paper, Au plasmons and their synergistic effects with $\mathrm{ZnO}$ nanorods (ZNs) have been investigated for photoelectrochemical (PEC) water splitting application. Au plasmons and ZNs are deposited electrochemically. Au modified nanostructures have absorption in the visible region as plasmons enhance charge transfer and inhibit charge recombination. ZNs modified with Au (deposition duration $\square 60 \mathrm{~s}$ ) has a photo-current density of $\square 660 \mu \mathrm{A} \mathrm{cm}^{-2}$, at a bias of 1.0V/SCE. X-ray diffraction and scanning electron microscopy were used to study the structure and surface morphology of fabricated photoanodes. UVVisible absorption and Photoluminescence spectroscopy were used for optical characterization. We have recorded current-voltage measurements and photo-conversion efficiency measurements to substantiate our observations of the synthesized photoanodes for prospective application in PEC splitting of water. We have also carried out Mott-Schottky, and electrochemical impedance spectroscopy analysis. The analysis reveals that Au modified ZNs based photoanodes are a better proposition than their bare counterparts for PEC water splitting application.
\end{abstract}

KEYWORDS: Photo-current; Plasmons; Photoelectrochemical; Zinc oxide 


\section{1: INTRODUCTION}

Sustainable energy economy can be achieved by converting solar energy into chemical fuels, for which photoelectrochemical (PEC) water splitting is the most promising route. PEC splitting of water utilizes the sun's astounding potential and readily available water to produce hydrogen [1-5]. In PEC cells, the semiconductor material is the most critical component. It should have sizeable visible spectrum absorption, straddling band edges, large lifetime of charge carriers, high carrier mobility, must be stable and economical $[6,7]$. The essential kinetic and thermodynamic conditions to realize a single semiconductor is still elusive [8]. Photoanodes based on Si and III-V semiconductors have exhibited record STH efficiency value up to $19.3 \%$, but these materials suffer from poor stability [9]. These semiconductors satisfy a bunch of mandatory conditions, but they are associated with high manufacturing costs.

Moreover, long-term device durability is compromised due to poor stability in PEC conditions. Earthabundant metal oxides, such as $\mathrm{ZnO}, \mathrm{TiO}_{2}, \mathrm{WO}_{3}, \alpha-\mathrm{Fe}_{2} \mathrm{O}_{3}$, and $\mathrm{BiVO}_{4}$, exhibit outstanding properties and can be viable options for PEC cells [9]. They have low processing cost, high stability, low minority carrier diffusion length, high recombination, and low light absorption. Plasmonics has emerged as a powerful tool to overcome the general drawbacks of metal oxides by integrating with photoanodes and enhancing PEC cell's performance.

Plasmons have unusual optical properties. Their physical size is exceeded by absorption and scattering cross-section. A metal usually absorbs solar radiation and converts it into heat radiation, but plasmons have diverted researchers' interest to plasmon assisted photocatalysis. Photon absorption promotes nonequilibrium carrier distribution so that high energy carriers can tunnel out of the metal into high energy orbitals of the molecules in the vicinity and thereby catalyze the reaction. This mechanism is known as the hot carrier mechanism. This mechanism retards the electron-hole recombination and improves the PEC efficiency by acting as electron trap centers [10-12]. Numerous researchers have probed the hot electron phenomena for PEC activity, and various configurations have been probed such as $\mathrm{Ag} / \mathrm{Au} / \mathrm{TiO} \mathrm{O}_{2}[13,14]$, $\mathrm{Ag} / \mathrm{Au} \mathrm{ZnO}[15,16], \mathrm{Au} / \mathrm{Fe}_{2} \mathrm{O}_{3}$ [17], $\mathrm{Au} / \mathrm{BiVO}_{4}$ [18], $\mathrm{Au} / \mathrm{MOS}_{2}$ [19], $\mathrm{Au} / \mathrm{ZnFe}_{2} \mathrm{O}_{4}$ [20], $\mathrm{Au} / \mathrm{SrTiO}_{3}$ [21] and $\mathrm{Au} / \mathrm{CuO}$ [22]. In every case, hot electron phenomena have helped in improving the efficiency of the PEC process. So we were motivated to pick plasmonic material in conjunction with wide bandgap material for our experimental work. Au is one of the important plasmonic materials as It exhibits a hot electron 
phenomenon and has a high $Q$ factor. Q-factor is responsible for high plasmonic strength, and Au has an inherent high Q-factor [23]. Moreover, for PEC application, $\mathrm{ZnO}$ is the most studied material [23-27]. ZnO is a direct band gap material $(3.2 \mathrm{eV})$ with high electron mobility and exciton binding energy. ZnO band edges straddle well with the redox potentials, and it is reasonably stable at $\mathrm{pH}$ 7.0. $\mathrm{ZnO}$ has poor absorption in the visible region, its prominent drawback $[28,29]$. To increase absorption in the visible region in $\mathrm{ZnO}$ for PEC splitting, doping is an effective strategy, but it has its limitations [30-33].

We have synthesized ZNs thin films by electrodeposition method, a straightforward and versatile method for depositing thin films. Moreover, one-dimensional nanostructures exhibit better charge transport properties compared to their mesoporous counterparts. In electrodeposition, experimental parameters can be tuned to control the size and density of ZNs on the surface of the substrates [34]. Au plasmons were incorporated on ZNs through electrochemical deposition. The synthesized photoanodes ZNs-Au $\left.0.66 \mathrm{~mA} / \mathrm{cm}^{2}\right)$, had enhanced photo-current compared to bare ZNs photoanodes $\left(\square 0.32 \mathrm{~mA} / \mathrm{cm}^{2}\right)$ at a bias of 1.0 V/RHE. For PEC splitting of water, the present study investigates the effect of electrodeposited $\mathrm{Au}$ plasmons on ZNs-based photoanodes in distinct configurations. To evaluate different structural and optical properties of the fabricated photoanodes, x-ray diffraction (XRD), scanning electron microscope (SEM), energy-dispersive analysis (EDX), UV-Visible absorption spectroscopy, and Raman analysis were carried out. Current-voltage (J-V) characteristics, electrochemical impedance spectroscopy (EIS), Mott-Schottky (MS) analysis, and photo-conversion efficiency (PCE) measurements have been used to validate the obtained PEC water splitting results.

\section{2: MATERIALS AND METHODS}

\section{1: Synthesis of Au sensitized ZNs based photoanodes}

Electrochemical deposition of Au plasmons dispersed ZNs array was carried out in a 3-electrode cell. For synthesizing photoanodes conducting glass substrate (FTO) was used. Pt mesh and Saturated calomel electrode (SCE) were used as a counter electrode and a reference electrode. Prior to deposition, FTO coated glass substrates were cleaned using standard procedure [31]. An aqueous solution comprising of $5 \mathrm{mM} \mathrm{Zn}(\mathrm{NO} 3)_{2} \cdot 6 \mathrm{H}_{2} \mathrm{O}$, and $50 \mathrm{mM} \mathrm{NaNO}_{3}$ electrolyte bath sustained at a temperature of $85^{\circ} \mathrm{C}$ was used to synthesize ZNs. Step potentials of -1.3 and $-1.0 \mathrm{~V}$ were applied for 15 and $2000 \mathrm{~s}$, respectively. After deposition, thin films were cleaned using deionized water and then dried. To improve the crystallinity, ZNs 
based photoanodes were annealed in air at $600^{\circ} \mathrm{C}$. Further, Au plasmons were electrochemically loaded on ZNs photoanodes. After electrodeposition, all the fabricated thin films were dried at $100{ }^{\circ} \mathrm{C}$ for $1 \mathrm{hr}$ in the oven.

\section{2: Characterization and Measurement Setup}

Low angle $x$-ray diffraction (XRD) was used to determine the crystal structure of the synthesized photoanodes. Bruker D8 Advance, Germany, x-ray diffractometer equipped with Cu-Ka irradiation $(\lambda=$ $1.54 \AA$ ) , in the range of $\left(20^{\circ}-55^{\circ}\right)$ was used to record the diffractograms. SEM was used to analyze the nanostructure of $\mathrm{ZnO}$ and also Au deposited on it. It was recorded using a scanning electron microscope (JEOL JSM630A). UV-Visible spectroscopy was used to determine the film's absorption spectra, which was used to calculate the Tauc plot and bandgap energy of the given materials. It was recorded by UVNis spectrophotometer (JASCO V-670). I-V characteristic was used to measure the photoconductivity of synthesized photoanodes with different concentrations of Au plasmons. It was recorded using the Autolab PGSTAT302N instrument under dark and illumination. MS and EIS were recorded to calculate concentration, flat band potential, and lifetime of charge carriers, respectively. PL spectroscopy was used to investigate the defects present in the synthesized photoanodes. It was recorded by (Horiba Fluorolog) spectrophotometer. The excitation wavelength was $350 \mathrm{~nm}$.

\section{3: RESULTS AND DISCUSSION}

XRD was used to study the crystal structures, atomic spacing, and phase orientation of the synthesized photoanodes. It is based on the constructive interference of monochromatic x-ray, which is diffracted from the crystalline sample. The recorded XRD pattern is shown in figure 1, which consists of the XRD pattern of FTO (substrate), ZNs, and Au plasmons. It was recorded in the fraction angle range of $20^{\circ}$ to $55^{\circ}$. The peaks at $2 \theta \square 31.8^{\circ}, 34.5^{\circ}, 36.3^{\circ}, 47.8^{\circ}$ are assigned to (100), (002), (101), (102) reflection planes indicate ZNs wurtzite structure. The narrow and strong diffraction peaks indicate the crystalline nature since the crystallite size varies inversely with the crystallite size. All the diffraction peaks reveal hexagonal wurtzite structure having lattice constants of 3.28 and $5.25 \AA$ for ZNs. The peaks at $2 \theta \square 38.3^{\circ}, 44.5^{\circ}$ are assigned to (111) and (200) reflection planes, which identify the Au plasmons and also indicate the crystal structure is face-centered cubic (FCC) with the lattice constant $4.2 \AA$. All the diffraction peaks for Au plasmons deposited on ZNs are present in all the photoanodes with different deposition times (30, 45, 60, $75 \mathrm{~s})$. 
Some prominent peaks of Au merge with the diffraction peaks of $\mathrm{ZnO}$. The intensity of each peak related to Au plasmons increases with Au concentration on the ZNs layer. For instance, the peak of (111) at $2 \theta \square$ $38.3^{\circ}$ (for $75 \mathrm{~s}$ ) has a considerable increment in intensity than $60 \mathrm{~s}, 45 \mathrm{~s}$, and $30 \mathrm{~s}$. It can be linked to the presence of high crystallinity of Au plasmons. These peaks prove that the ZNs with Au plasmons have been deposited successfully on the substrate. Furthermore, these results were substantiated by scanning electron microscopy micrographs.

Figure 2 shows the synthesized photoanode's SEM images, including ZNs and ZNs with Au plasmons (loaded for different time durations). The images indicate that the $\mathrm{ZnO}$ has taken nanorod form, and $\mathrm{Au}$ plasmons are present on their surface. Nanorods are the best among other nanostructures like nanotubes, nano-belts, nano-springs, nano-spiral, and nano-rings. Due to their one-dimensional structure, ZNs can facilitate more efficient carrier transports because of decreased grain boundaries, surface defects, disorders, and discontinuous interface.

From figure 2 it is clear, well-aligned ZNs have grown on the FTO substrate. The length of ZNs is $1.5 \mu \mathrm{m}$, and the diameter is approximately in the range of $100-200 \mathrm{~nm}$. It was calculated by Image $\mathrm{J}$ software which the average value is $150 \mathrm{~nm}$. As we see from figure 2(b1), a salient change occurs in the growth morphology after incorporating Au plasmons. The figures of 2(b)-(e) illustrate that the Au plasmons are uniformly distributed over ZNs. ZNs maintain their vertically-oriented characteristics even after incorporating Au; although, time deposition durations were different, leading to variation in Au's distribution density and size over ZNs.

The average diameter of Au plasmons obtained by image $\mathrm{J}$ software and is found $\square 136 \mathrm{~nm}$. However, the diameter of the Au plasmons is different for different photoanodes. Since they are distributed over the photoanodes surface, Au plasmons dispersion leads to a plasmon active surface. According to the given plots, the average diameter of ZNs is $100-200 \mathrm{~nm}$. Similarly, the diameter of Au plasmons is estimated around 115, 129, 140, $171 \mathrm{~nm}$ for different photoanodes with 30, 45, 60, $75 \mathrm{~s}$ deposition time, respectively. The presence of plasmons is solely responsible for the thermal effects. There is a difference between the actual $\left(T_{A}\right)$ and the measured temperature $\left(T_{M}\right)$ of the synthesized photoanodes. The reaction rate, according to Arrhenius theory, is given as,

$$
R \quad a \quad \exp \left(-E_{a} / k_{B} T\right)
$$


where $E_{a}$ is the activation energy and $k_{B}$ is the Boltzmann constant. If $T_{M}$ is less than the $T_{A}$ of the photoanode, it appears that the reaction rates overshoot the Arrhenius law [10]. A simple correlation between the photoanode temperature, $\mathrm{T}_{\mathrm{M}}$, and the incident illumination intensity linc,

$$
\mathrm{T}_{\mathrm{A}}=\mathrm{T}_{\text {dark }}+\mathrm{a} \mathrm{l}_{\text {inc }}=\mathrm{T}_{\mathrm{M}}+\mathrm{a} \mathrm{linc}_{\text {inc }}
$$

Where $T_{\text {dark }}$ is reactor temperature in the dark.

Here ' $a$ ' is the photothermal conversion coefficient, which depends on several parameters such as material density number, illumination wavelength, size, and plasmonic material. The slow heating effect due to illumination can be easily incorporated by including a non-linear term linc, with temperature [10]. To get the range of light absorption and Au plasmons' effect on the top of ZNs photoanodes, UV-Visible spectra were recorded. Figure 3 shows the absorption spectra and Tauc plot of all synthesized photoanodes. The absorption range of photoanodes changes with respect to Au plasmons' deposition duration [Figure 3(a)]. As the concentration of Au plasmons increases, the absorption ranges increase in the visible region. The interaction between light and Au plasmons is induced by hot electrons. The bare ZNs photoanode exhibits an absorption edge at $\square 370 \mathrm{~nm}$. The Tauc plot [Figure 3(b)] defines its band edge position as $\square 3.2 \mathrm{eV}$. It means only the photons with energy greater than this value can be absorbed, corresponding to wavelengths less than $387 \mathrm{~nm}$. As the Au plasmons contribute to the absorption of light, this rate varies remarkably. The ZNs photoanode with Au plasmons for $30 \mathrm{~s}$ deposition time exhibits an absorption range less than $\square 390 \mathrm{~nm}$, which corresponds to $\square 3.12 \mathrm{eV}$. It indicates that the band edge position is decreased in Au-PNPs, resulting in an enhanced absorption range toward the visible region. Similarly, the band edge positions for ZNs-Au- 45, 60, 75 s are obtained at $\square 3.152,3.13$, and $3.07 \mathrm{eV}$.

The PL spectroscopy analysis further confirms results obtained from UV-Visible spectroscopy. By measuring the luminescence spectrum, it is possible to observe material imperfections and impurities. Figure 4 shows the PL spectrum of all synthesized photoanodes. The laser beam with a wavelength of $350 \mathrm{~nm}$ was used as an excitation wavelength. Figure 4(a) shows the emission spectra of all synthesized photoanodes as a function of wavelength, whereas figure 4(b) shows emission spectra as a function of energy. For bare ZNs photoanodes, a strong emission characteristic of the excitonic band is observed in the UV region, and a small amount in the visible region, which are centered at $359 \mathrm{~nm}, 382 \mathrm{~nm}, 402 \mathrm{~nm}$, and $538 \mathrm{~nm}$ correspond to energy $3.45 \mathrm{eV}, 3.23 \mathrm{eV}, 3.08 \mathrm{eV}$, and $2.31 \mathrm{eV}$ respectively. The highest peak 
is located at $3.23 \mathrm{eV}$, indicating strong emission in the $\mathrm{UV}$ region and describing the bandgap transition. As plasmonic $\mathrm{Au}$ is attributed to the $\mathrm{ZNs}$, it causes enhancement of $\mathrm{PL}$ properties and large separation of excited electron-hole pairs upon visible light excitation. As we observe in figure 4(a), the synthesized photoanodes exhibit a broad emission band in the visible region. The largest emission is concentrated for ZNs-Au-30 s. It shows a good peak at $443 \mathrm{~nm}$ with high intensity and two peaks with low intensity comparably at $415 \mathrm{~nm}$ and $537 \mathrm{~nm}$ in the visible region. The peak at $537 \mathrm{~nm}$ still has high intensity than the peak at $537 \mathrm{~nm}$ of bare ZNs photoanode. On the other hand, the central emission peaks of ZNs-Au describes the emission of band gap transition and higher electron-hole recombination between the conduction band the sublevel, which is created in the bandgap due to Au plasmons. Consequently, the excitonic emission band is shifted in Au plasmons from the UV region to the visible region.

$\mathrm{J}-\mathrm{V}$ characteristics, EIS, and MS analysis were carried out to understand the PEC performance of the synthesized photoanodes. The PEC activity for all the synthesized photoanodes was recorded by linear sweep voltammetry (LSV) using three-electrode cells in the range 1.0 to $1.0 \mathrm{~V}$ versus SCE in the $0.5 \mathrm{M}$ $\mathrm{N}_{2} \mathrm{SO}_{4}$ electrolyte. The result is shown in figure 5(a). The current was recorded in the dark in the first step, but a small amount of current density was still observed. This current can be due to a non-faradic reaction. In the second step, the photoelectrode was illuminated by light, and a large amount of current was observed. Upon illumination, the photoelectrodes exhibit a direct photoexcitation, which leads to the generation of electron-hole pairs. Electrons migrate toward $\mathrm{Pt}$ (counter electrode), where $\mathrm{H}_{2}$ would be produced by reducing protons. The holes react with water molecules to evolve $\mathrm{O}_{2}$. Photocurrent density for bare ZNs at $1.0 \mathrm{~V} / \mathrm{SCE}$ under the illumination is around $324 \mu \mathrm{A} / \mathrm{cm}^{2}$ and for ZNs-Au-30s, ZNs-Au-45s, ZNs-Au-60s, ZNs-Au-75s are $420 \mu \mathrm{A} / \mathrm{cm}^{2}, 540 \mu \mathrm{A} / \mathrm{cm}^{2}, 660 \mu \mathrm{A} / \mathrm{cm}^{2}, 581 \mu \mathrm{A} / \mathrm{cm}^{2}$ respectively. The synthesized photoanodes with Au plasmons exhibit more photo-current density than bare photoanode. The plasmonic layer of $\mathrm{Au}$ increases the photo-current density since the confined plasmonic effect of $\mathrm{Au}$ clusters present on the top of ZNs helps to enhance localized field strength, leading to an increase in the light absorption coefficient. According to the investigation, Au plasmons absorb light and evolve hot electrons. These hot electrons insert in the conduction band of $\mathrm{ZnO}$, and further are drifted toward the cathode, leading to enhancement in the photo-current density. As the concentration of Au plasmons is increased up to a certain limit on the surface of ZNs, the photo-current density is increased. 
Nevertheless, when it exceeds the limit, the photo-current density is decreased. For instance, the ZNs-Au75 s exhibits less photo-current density than ZNs-Au-60s. The high photo-current density is obtained from ZNs-Au-60s, which is around $660 \mu \mathrm{A} / \mathrm{cm}^{2}$. PCE of photoanodes has been calculated using,

$$
\mathrm{PCE}=\frac{\mathrm{J}_{\mathrm{Ph}} \times\left(1.23-\left|\mathrm{V}_{\text {Bias }}\right|\right)}{\mathrm{P}_{\text {Light }}}
$$

Where $\mathrm{JPh}_{\mathrm{Ph}}$ is the photo-current density at given $\mathrm{V}_{\text {Bias, }} \mathrm{V}_{\text {Bias }}$ is applied voltage between photoanode and counter electrode, and $\mathrm{P}_{\text {Light }}$ is the power density of incident light $\left(100 \mathrm{~mW} / \mathrm{cm}^{2}\right)$. Figure $5(\mathrm{~b})$ shows the photo-conversion efficiency of photoanodes for Au plasmons loaded for different time durations. The maximum PCE is obtained for ZNs-Au-60s, which is $\square 0.38 \%$, whereas for bare ZNs, the PCE is $\square 0.20 \%$. The "hot electron mechanism" can be used to explain two important phenomena. Foremost, it explains the inherent capability of high-energy electrons tunneling to the adjacent semiconductor through the Schottky barrier. These electrons can be used for photodetection at frequencies lower than the bandgap of the semiconductor. Secondly, noble metals, which are normally considered as bad catalysts, contribute immensely to catalysis reactions when they are subjected to visible electromagnetic radiation.

Plasmons provide energy pathways with low activation to electrons. The presence of hot electrons help in the reduction of activation energy and provide favorable reaction pathways as a function of number density. Loading of plasmons helps in circumventing the well-known limitation associated with photocatalysis occurring at high temperatures. EIS is an experimental technique that determines the dielectric properties of synthesized photoanodes and measures the impedance of them over a series of frequencies. The corresponding Nyquist and Bode plots are shown in figure 6. The arc diameters typically represent the effective dissociation of photo-generated electron-hole pairs and their prolonged lifetime. The smaller arc diameter of ZNs-Au photoanodes describes the prolonged lifetime of photo-generated charge carriers compared to the bare ZNs photoanodes [Figure 6(a)]. As the Au plasmons layer takes part in the operation, it promotes the transfer of electrons within the semiconductor and restrains the electron/hole recombination. The lifetime of charge carriers in the photoanodes has been estimated using the following relation,

$$
\tau=\frac{1}{2 \pi f_{\max }}
$$

Where $f_{\max }$ is the frequency at the maximum phase angle in the Bode plot [Figure 6(b)]. 
The lifetimes of photoelectrons for the bare-ZNs and ZNs-Au-60s photoanodes are obtained $123 \mathrm{~ms}$ and $170 \mathrm{~ms}$, respectively. The most extended lifetime is predicted for ZNs-Au-60s photoanode.

To investigate the core mechanism involved in embedded plasmonic configuration and properties such as flat band potential (built-in potential), doping density, and Helmholtz capacitance MS was studied. Figure 7 shows the MS plot from which capacitance was calculated and is used to estimate the density of charge carriers,

$$
\frac{1}{\mathrm{C}^{2}}=\left(\frac{2}{\mathrm{e} \varepsilon_{0} \varepsilon_{\mathrm{r}} \mathrm{N}_{\mathrm{D}} \mathrm{A}^{2}}\right)\left(\mathrm{V}-\mathrm{V}_{\mathrm{FB}}-\frac{\mathrm{KT}}{\mathrm{e}}\right)
$$

Where $\mathrm{C}$ is the capacitance of the space-charge region of the film at potential $\mathrm{V}, \mathrm{V}_{\mathrm{FB}}$ is flat band potential, $\square \mathrm{r}$ is a dielectric constant which is $\square 8$ for bulk $\mathrm{ZnO}, \mathrm{N}_{\mathrm{D}}$ free carrier concentration, Kis the Boltzmann constant, and $\mathrm{T}$ is the absolute temperature. The free charge carrier concentration can be given as,

$$
\mathrm{N}_{\mathrm{D}}=\frac{2}{\mathrm{e} \varepsilon_{0} \varepsilon_{\mathrm{r}} \mathrm{A}^{2} \text { (Slope) }}
$$

All the synthesized photoanodes exhibited positive slopes, depicting the n-type nature of $\mathrm{ZnO}$ photoanodes. In the given plot, the slope is used to determine the doping density $\left(\mathrm{N}_{\mathrm{d}}\right)$, and intercepts with the $x$-axis define the flat band potential $\left(\mathrm{V}_{\mathrm{FB}}\right)$. The flat band potential can be calculated from the intercept of the plot as,

$$
\mathrm{V}_{\mathrm{FB}}=-\left[\frac{(\text { Intercept })}{(\text { Slope })}+\frac{\mathrm{KT}}{\mathrm{e}}\right]
$$

Where $\mathrm{kT} / \mathrm{e}$ is a correction factor $\square 0.025 \mathrm{~V}$ that does not affect $\mathrm{V}_{\text {fb }}$ and intercept with slope can be defined from the plot after the linear fitting. The $N_{d}$ for $Z N s$ photoanode is around $2.0 \times 10^{21} / \mathrm{cm}^{3}$, which has increased for ZNs with the incorporation of Au plasmons, as shown in Table1.

Table 1: Flat band potential $\left(\mathrm{V}_{\mathrm{fb}}\right)$, donor density $\left(\mathrm{N}_{\mathrm{d}}\right)$, depletion layer width $(\mathrm{W})$ of synthesized photoanodes at $1.0 \mathrm{~V}$

\begin{tabular}{|l|c|c|c|}
\hline Samples & Flat band potential (V vs. RHE) & Donor density $\left(\mathbf{c m}^{-3}\right)$ & Depletion layer width (nm) \\
\hline ZNs-Bare & -0.48 & $2.00 \times 10^{21}$ & 0.80 \\
\hline ZNs-Au-30 s & -0.58 & $1.08 \times 10^{22}$ & 0.36 \\
\hline ZNs-Au-45 s & -0.54 & $1.40 \times 10^{22}$ & 0.31 \\
\hline ZNs-Au-60 s & -0.50 & $3.74 \times 10^{22}$ & 0.18 \\
\hline ZNs-Au-75 s & -0.55 & $3.03 \times 10^{22}$ & 0.21 \\
\hline
\end{tabular}


The ZNs-Au photoanodes exhibit more donor density than ZNs. At an applied potential $1.0 \mathrm{~V}$, the calculated space charge layers were $0.80 \mathrm{~nm}$ for ZNs-bare and $0.21 \mathrm{~nm}$ for ZNs-Au-75s.The efficient charge separation transport and enhancement of PEC performance can be interpreted by charge carrier density. The enhancement in the carrier density confirms the efficiency of these two factors. It should be noted that these carrier densities were obtained based on the surface area of photoanodes exposed to the electrolyte. A positive shift is observed in flat band potential, suggesting a decrease in the binding band edge. Hence, donor density and bulk charge transport properties were improved via Au plasmons incorporation in ZNs.

\section{CONCLUSIONS:}

We have successfully synthesized Au dispersed ZNs based photoanodes by the two-step PEC deposition method. The results indicate that the plasmonic layer of Au enhances the light absorption properties of synthesized photoanodes. All ZNs-Au photoanodes exhibited enhanced PEC response compared to bare ZNs. The ZNs-Au-60s had shown a higher photo-current density ( $\square 660 \mu \mathrm{A} / \mathrm{cm}^{2}$ at a bias of $\left.1.0 \mathrm{~V} / \mathrm{SCE}\right)$ than all synthesized photoanodes. The acquired PEC efficiency of ZNs-Au-60s photoanode under light illumination was $0.38 \%$, which is 1.9 times of PEC efficiency for ZNs. The increased absorption in the visible region due to the surface plasmon resonance effect and the decreased photo-generated electronhole recombination leads to a remarkably enhanced PEC performance. The UV-Visible proved that the ZNs-Au-60 s photoanode has a good absorption band in the visible region. The bandgap values shifted toward the visible region from 3.20 to $3.07 \mathrm{eV}$ for ZNs and ZNs-Au-60s photoanodes. EIS described that photoelectron lifetime in the $\mathrm{ZnO}-\mathrm{Au}-60$ s photoanode is remarkably more than bare $\mathrm{ZNs}$ and is $170 \mathrm{~ms}$, while for bare ZNs, it is $123 \mathrm{~ms}$. The research provides a straightforward and effective method for constructing and designing Au plasmons embedded ZNs-based photoanodes with high PEC performance.

\section{ACKNOWLEDGEMENTS:}

Vidhika Sharma, Mohit Prasad, and Sandesh Jadkar are thankful to Indo-French Centre for the Promotion of Advanced Research-CEFIPRA, Department of Science and Technology, New Delhi, for special financial support. Sandesh Jadkar is also thankful to UGC for financial support under the UPE program. Vidya Doiphode, Ashvini Punde, Pratibha Shinde, Yogesh Hase, and Ashish Waghmare are thankful to the 
Ministry of New and Renewable Energy, Government of India for financial support under the National Renewable Energy Fellowship (NREF) program.

\section{REFERENCES}

[1] Nocera DG (2012) The artificial leaf. Acc Chem Res 45(5):767-776

[2] Tachibana Y, Vayssieres L, Durrant JR (2012) Artificial photosynthesis for solar water-splitting. Nat Photon 6:511-518

[3] Dincer I, Acar C (2015) Review and evaluation of hydrogen production methods for better sustainability. Int J Hydrog Energy 40(34):11094-11111

[4] Acar C, Dincer I (2014) Experimental investigation and analysis of a hybrid photoelectrochemical hydrogen production system. Int J Hydrog Energy 39(28):15362-15372

[5] Li Z, Luo W, Zhang M, Feng J, Zou Z (2013) Photoelectrochemical cells for solar hydrogen production: current state of promising photoelectrodes, methods to improve their properties and outlook. Energy Environ Sci 6:347-370

[6] Bak T, Nowotny J, Rekas M, Sorrell CC (2002) Photo-electrochemical hydrogen generation from water using solar energy. Materials-related aspects. Int J Hydrog Energy 27:991-1022

[7] Chen X, Shen S, Guo L, Mao SS (2010) Semiconductor-based photocatalytic hydrogen generation. Chem Rev 110:6503-6570

[8] Chen Z, Dinh H, Miller E (2013) Photoelectrochemical water splitting: standards, experimental, methods and protocols. Springer, New York

[9] Prasad M, Sharma V, Rokade A, Jadkar S (2018) Photoelectrochemical cell: a versatile device for sustainable hydrogen production. Photoelectrochemical Sol Cells 30:59-119

[10] Sivan Y. and Dubi Y (2020) Recent developments in plasmon-assisted phototcatalysis-A personal perspective. Appl. Phys. Lett. 117, 130501

[11] Hou W, Cronin SB (2013) A review of surface plasmon resonance-enhanced photocatalysis. Adv Funct Mater 23:1612-1619

[12] Rycenga M, Cobley CM, Zeng J, Li W, Moran CH, Zhang Q, Qin D, Xia Y (2011) Controlling the synthesis and assembly of silver nanostructures for plasmonic applications. Chem Rev 111:36693712 
[13] Wu F, Hu X, Fan J, Liu E, Sun T, Kang L, Hou W, Zhu C, Liu H (2013) Photocatalytic activity of $\mathrm{Ag} / \mathrm{TiO}_{2}$ nanotube arrays enhanced by surface plasmon resonance and application in hydrogen evolution by water splitting. Plasmonics 8(2):501-508

[14] Lee J, Mubeen S, Ji X, Stucky GD, Moskovits M (2012) Plasmonic photoanodes for solar water splitting with visible light. Nano Lett 12:5014-5019

[15] Wei Y, Ke L, Kong J, Liu H, Jiao H, Lu X, Du H, Sun XW (2012) Enhanced photoelectrochemical water-splitting effect with a bent $\mathrm{ZnO}$ nanorod photoanode decorated with $\mathrm{Ag}$ nanoparticles. Nanotechnology 23:235401-235409

[16] Zhang X, Liu Y, Kang Z (2014) 3D branched ZnO nanowire arrays decorated with plasmonic Au nanoparticles for high-performance photoelectrochemical water splitting. Appl Mater Interfaces $6: 4480-4489$

[17] Li J, Cushing SK, Zheng P, Meng F, Chu D, Wu N (2013) Plasmon-induced photonic and energytransfer enhancement of solar water splitting by a hematite nanorod array. Nat Commun 4:26512659

[18] Zhang I, Lin CY, Valev VK, Reisner E, Steiner U, Baumberg JJ (2014) Plasmonic enhancement in BiVO4 photonic crystals for efficient water splitting. Small 10:3970-3978

[19] Yin Z, Chen B, Bosman M, Cao X, Chen J, Zheng B, Zhang H (2014) Au nanoparticle-modified MoS2 nanosheet-based photoelectrochemical cells for water splitting. Small 10:3537-3543

[20] Sheikh A, Yengantiwar A, Deo M, Kelkar S, Ogale S (2013) Near-field plasmonic functionalization of light harvesting oxide-oxide heterojunctions for efficient solar photoelectrochemical water splitting: the AuNP/ZnFe2O4/ZnO system. Small 9:2091-2096

[21] Zhong Y, Ueno K, Mori Y, Shi X, Oshikiri T, Murakoshi K, Inoue H, Misawa H (2014) Plasmonassisted water splitting using two sides of the same $\mathrm{SrTiO}_{3}$ single-crystal substrate: conversion of visible light to chemical energy. Angew Chem Int Ed 53:10350-10354

[22] Kung WT, Pai YH, Hsu YK, Lin CH, Wang CM (2013) Surface plasmon assisted CuxO photocatalyst for pure water splitting. Opt Express 21:A221-A228

[23] Yang X, Wolcott A, Wang G, Sobo A, Fitzmorris RC, Qian F, Zhang JZ, Li Y (2009) Nitrogen-doped $\mathrm{ZnO}$ nanowire arrays for photoelectrochemical water splitting. Nano Lett 9:2331-2336 
[24] Gupta M, Sharma V, Shrivastava J, Solanki A, Singh AP, Satsangi VR, Dass S, Shrivastav R (2009) Preparation and characterization of nanostructured $\mathrm{ZnO}$ thin films for photoelectrochemical splitting of water. Bull Mater Sci 32:23-30

[25] Han J, Liu Z, Guo K, Wang B, Zhang X, Hong T (2015) High-efficiency photoelectrochemical electrodes based on $\mathrm{ZnIn}_{2} \mathrm{~S}_{4}$ sensitized $\mathrm{ZnO}$ nanotube arrays. Appl Catal B 163:179-188

[26] Hong T, Liu Z, Liu H, Junqi L, Zhang X, Han J, Guo K, Wang B (2015) Preparation and enhanced photoelectrochemical performance of selenite-sensitized zinc oxide core/shell composite structure. J Mater Chem A 3:4239-4247

[27] Yan L, Zhao W, Liu Z (2016) 1D ZnO/BiVO4heterojunction photoanodes for efficient photoelectrochemical water splitting. Dalton Trans 45:11346-11352

[28] Janotti A, Walle CGV (2009) Fundamentals of zinc oxide as a semiconductor. Rep Prog Phys $72: 126501-126529$

[29] Wang ZL (2004) Zinc oxide nanostructures: growth, properties and applications. J Phys Condens Matter 16:R829-R858

[30] Sharma V, Kumar P, Shrivastava J, Solanki A, Satsangi VR, Dass S, Shrivastav R (2011) Vertically aligned nanocrystalline $\mathrm{Cu}-\mathrm{ZnO}$ thin films for photoelectrochemical splitting of water. J Mater Sci 46:3792-3801.

[31] Sharma V, Kumar P, Singh N, Upadhyay S, Satsangi VR, Dass S, Shrivastav R (2012) Photoelectrochemical water splitting with nanocrystalline $\mathrm{Zn}_{1-\mathrm{x}} \mathrm{R} \mathrm{u}_{\times} \mathrm{O}$ thin films. Int $\mathrm{J}$ Hydrog Energy $37: 12138-12149$

[32] Sharma V, Dixit M, Satsangi VR, Dass S, Pal S, Shrivastav R (2014) Photoelectrochemical splitting of water with nanocrystalline $\mathrm{Zn}_{1-\mathrm{x}} \mathrm{Mn} \times \mathrm{O}$ thin films: first-Principle DFT computations supporting the systematic experimental endeavor. Int J Hydrog Energy 39:3637-3648

[33] Sharma V, Prasad M, Jadkar S, Pal S (2013) Influence of carbon and phosphorus doping on electronic properties of ZnO. J Mater Sci Mater Electron 27(12):12318-12322

[34] Peulon S, Lincot D (1996) Cathodic electrodeposition from aqueous solution of dense or open structured zinc oxide films. Adv Mater 8:166-170 


\section{FIGURE CAPTIONS}

Figure 01: XRD spectra: ZnO nanorods (ZNs), ZNs-Au for different Au deposition durations.

Figure 02: SEM images of synthesized photoanodes. a1) Bare ZNs, b1) ZNs-30 s, c1) ZNs-Au 45 s, d1) ZNs-Au 60 s, e1) ZNs-Au 75 s at low magnification (LM), a2) Bare ZNs, b2) ZNs-30 s, c2) Z-Ns-Au 45 s, d2) ZNs-Au $60 \mathrm{~s}$, e2) ZNs-Au $75 \mathrm{~s}$ at high magnification (HM).

Figure 03: UV-Visible absorption spectra: for bare ZNs, ZNs-Au-30 s, ZNs-Au-45 s, ZNs-Au-60 s, and ZNs-Au-75 s. Inset shows the Tauc plot used to estimate the bandgap.

Figure 04: PL spectra: for bare ZNs, ZNs-Au-30 s, ZNs-Au-45 s, ZNs-Au-60 s, and ZNs-Au-75 s a) Emission spectra as a function of wavelength $\mathbf{b}$ ) Emission spectra as a function of energy.

Figure 05: PEC characteristics of synthesized photoanodes a) J-V characteristics, b) photo-conversion efficiency.

Figure 06: a) Nyquist plot for bare ZNs and ZNs-Au-60 s photoanodes at $0.5 \mathrm{~V}$ under illumination in 0.5 $\mathrm{M} \mathrm{Na}_{2} \mathrm{SO}_{4}$, b) Bode plot of bare ZNs and ZNs-Au- $60 \mathrm{~s}$ at a bias potential of $0.5 \mathrm{~V}$ in light.

Figure 07: Mott-Schottky plots for ZNs-bare, ZNs-Au-30 s, ZNs-Au-45 s, ZNs-Au-60 s and ZNs-Au-75 s photoanodes. 
FIGURE 01

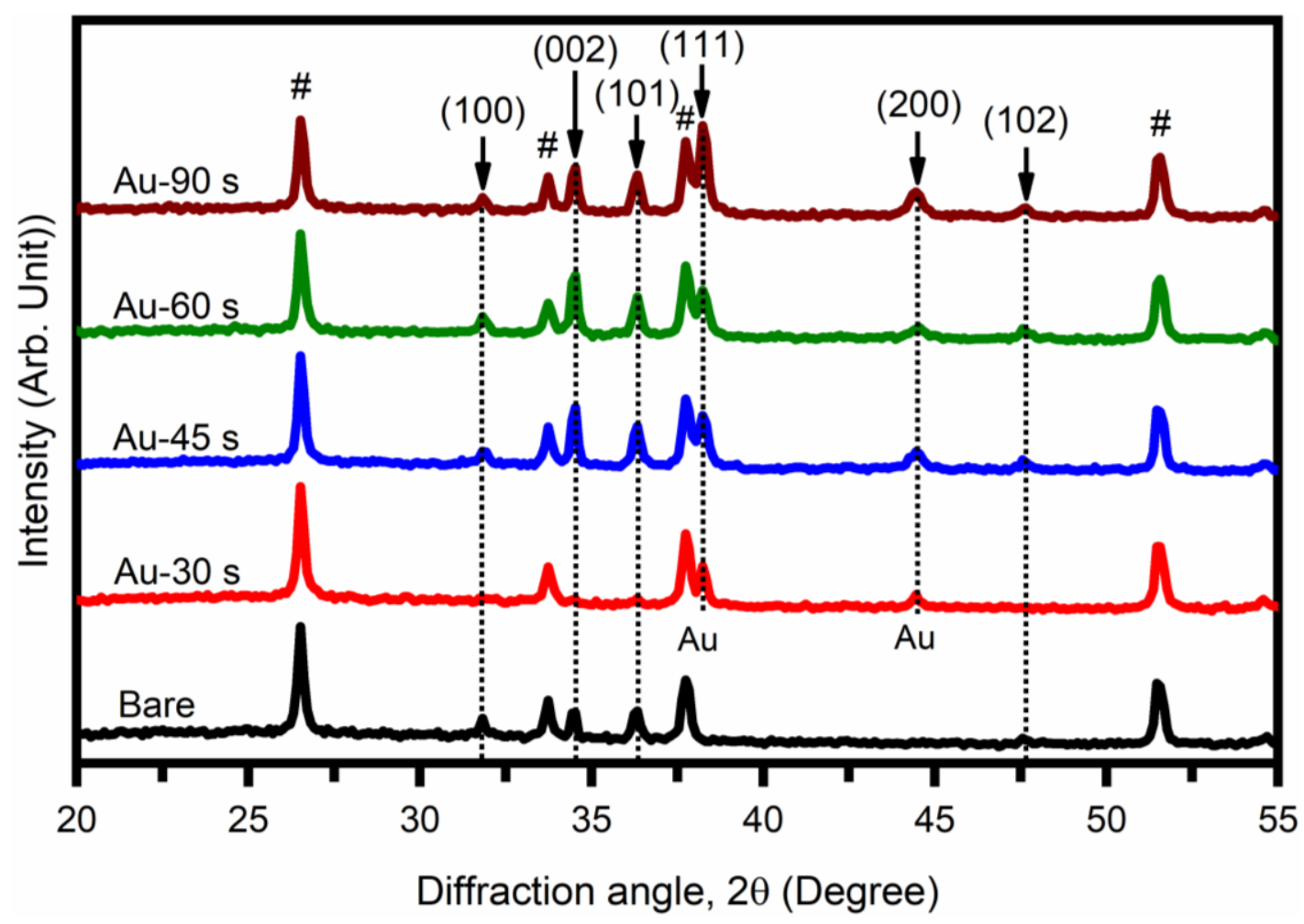


FIGURE 02
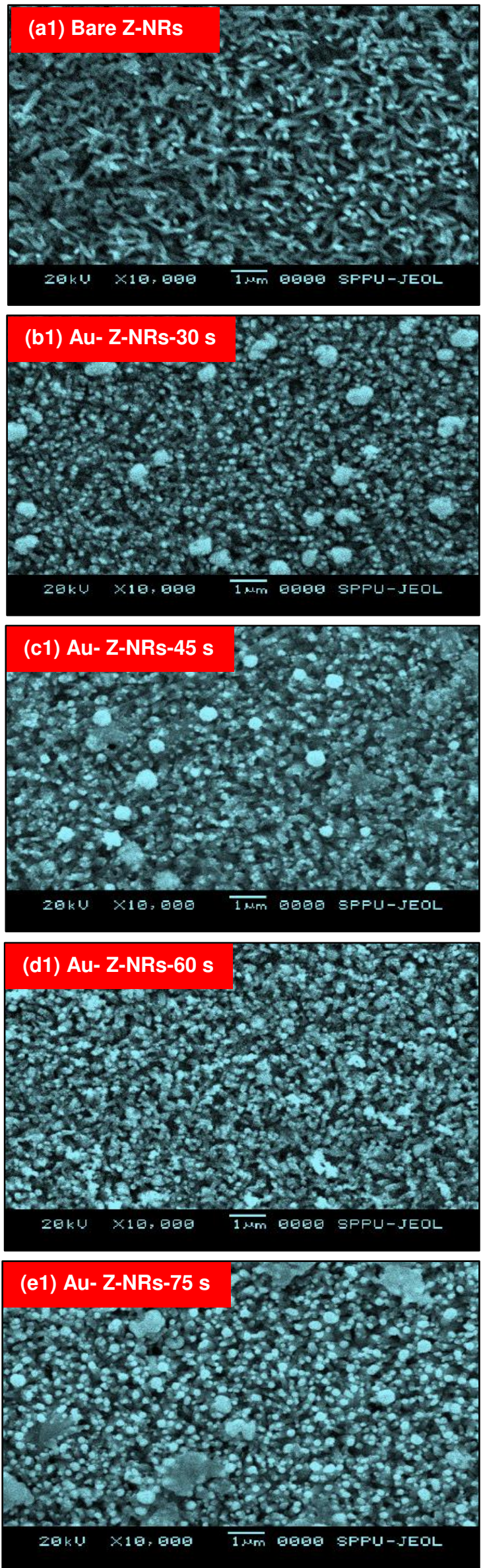
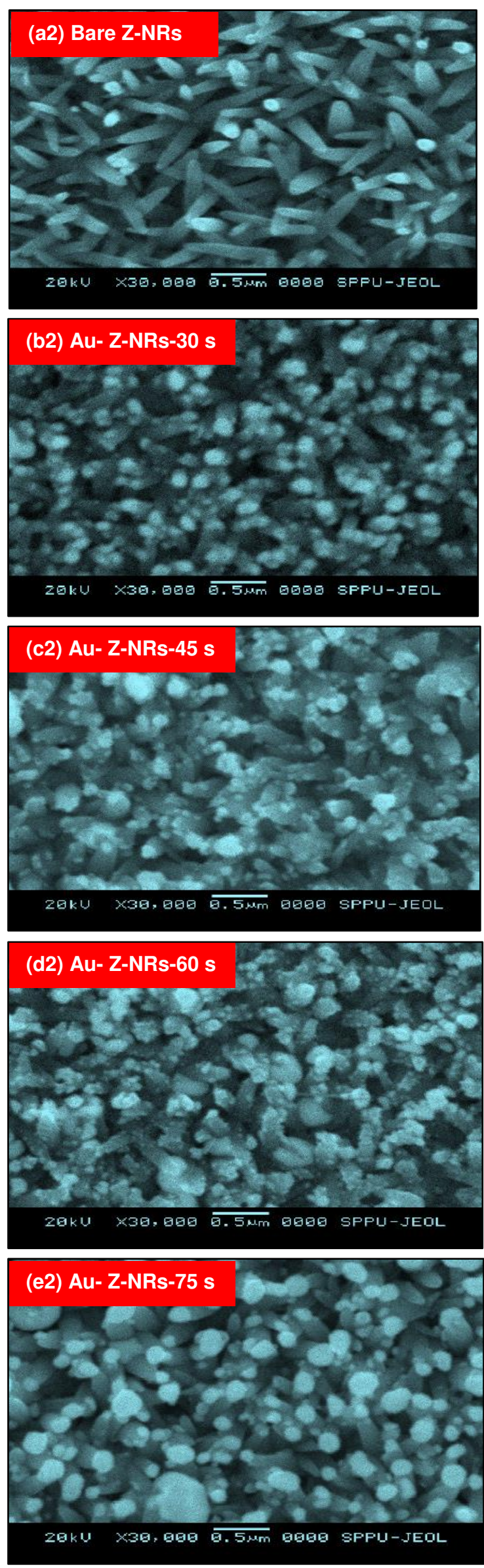
FIGURE 03
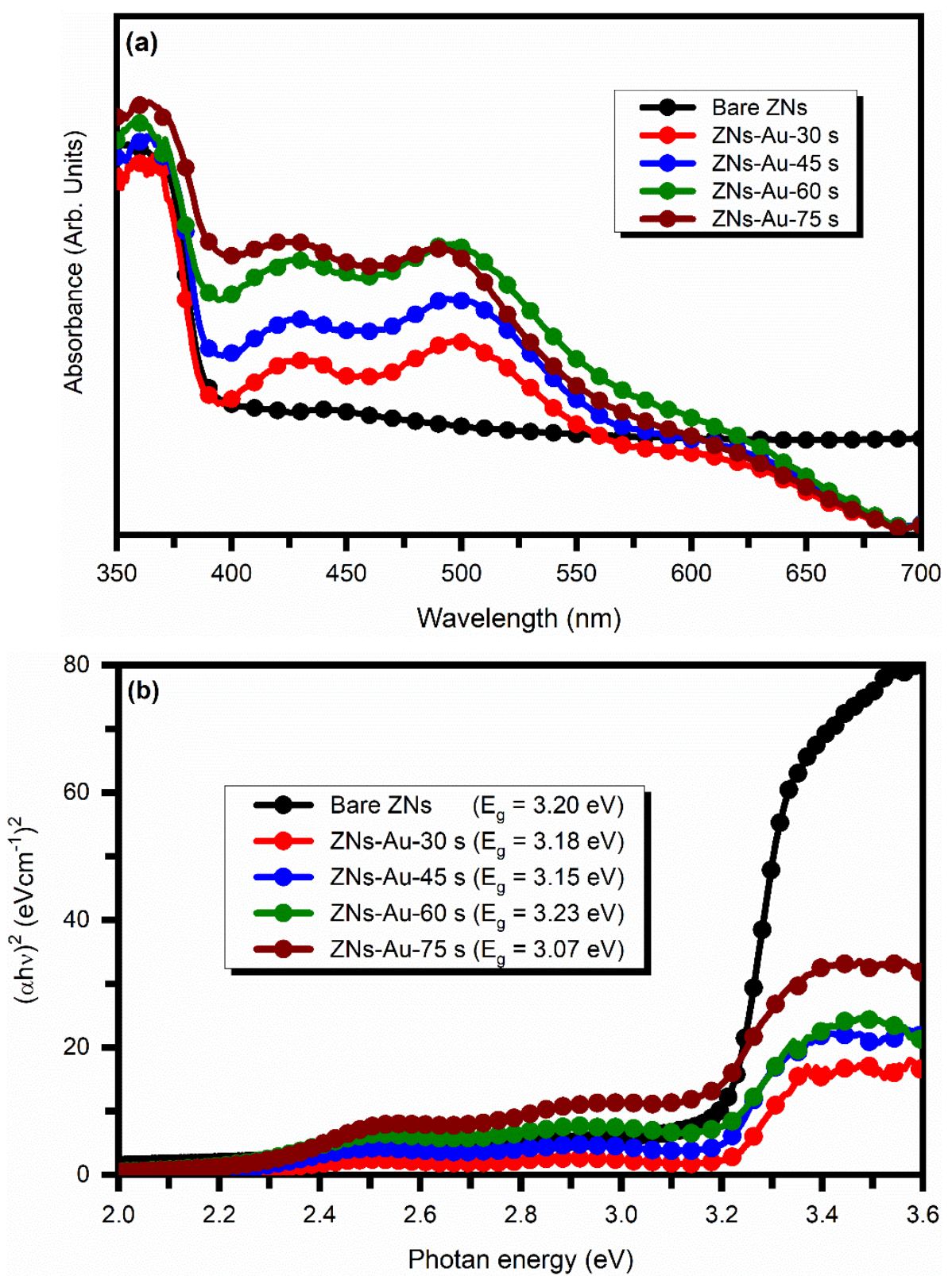
FIGURE 04
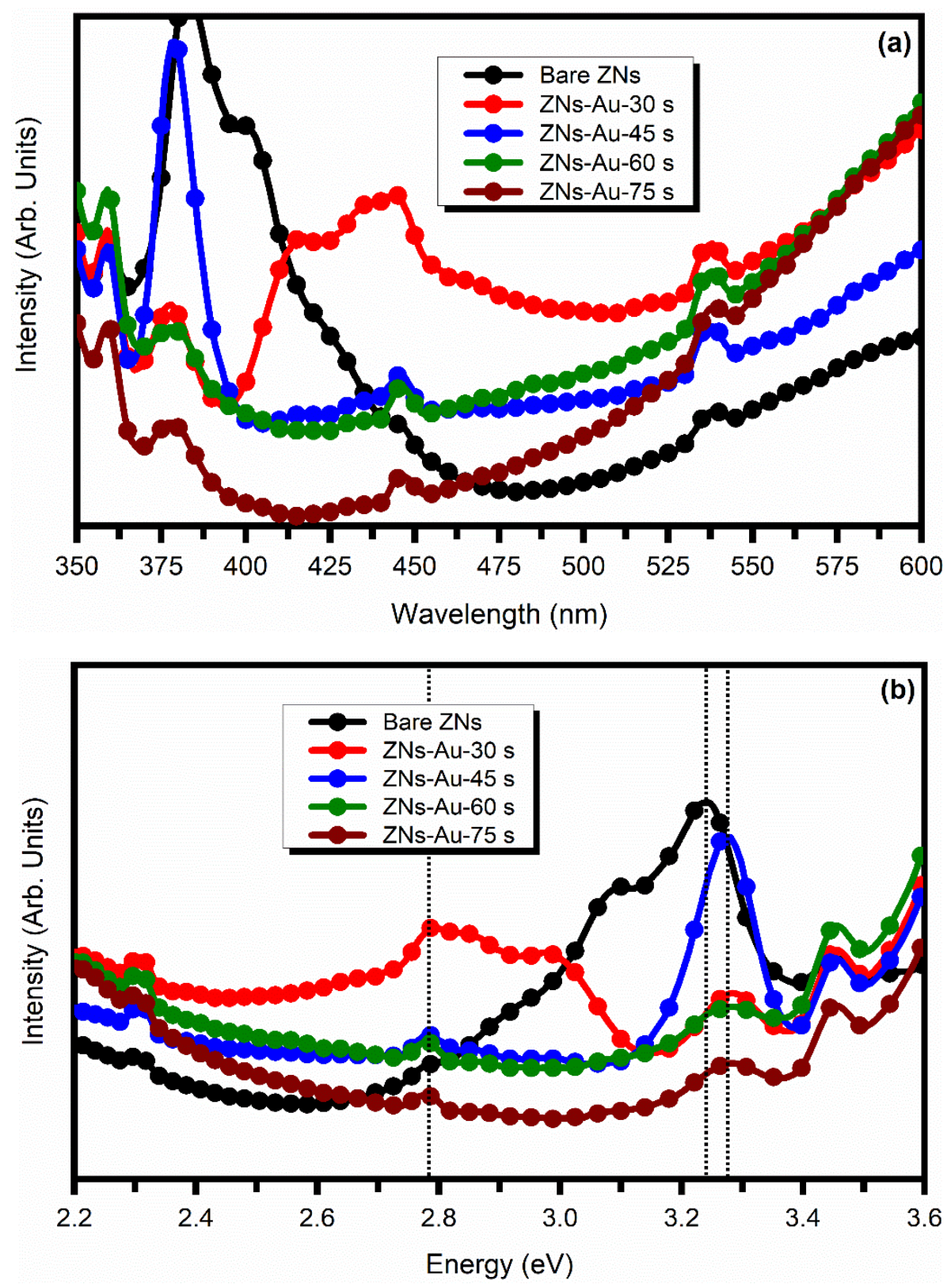
FIGURE 05
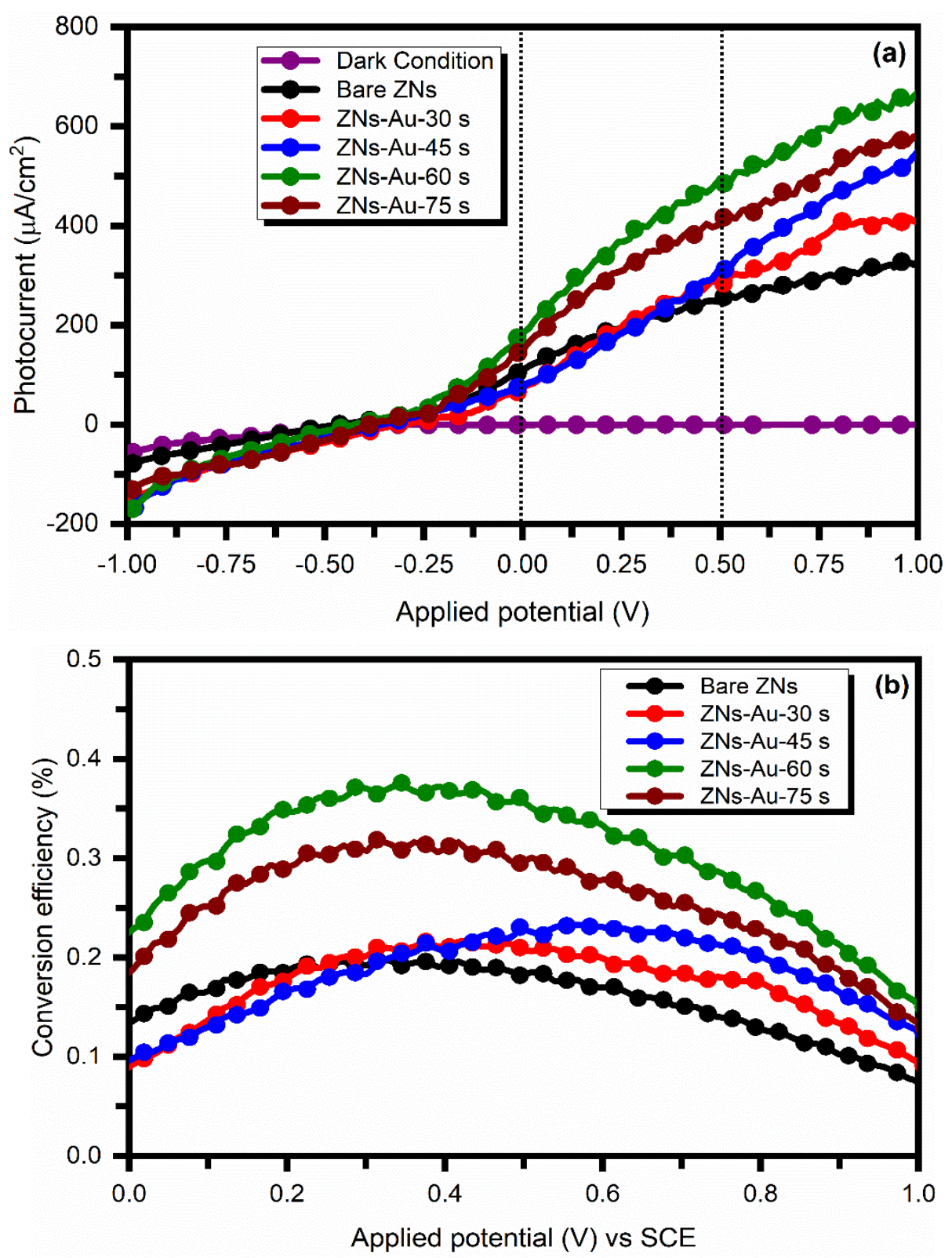
FIGURE 06
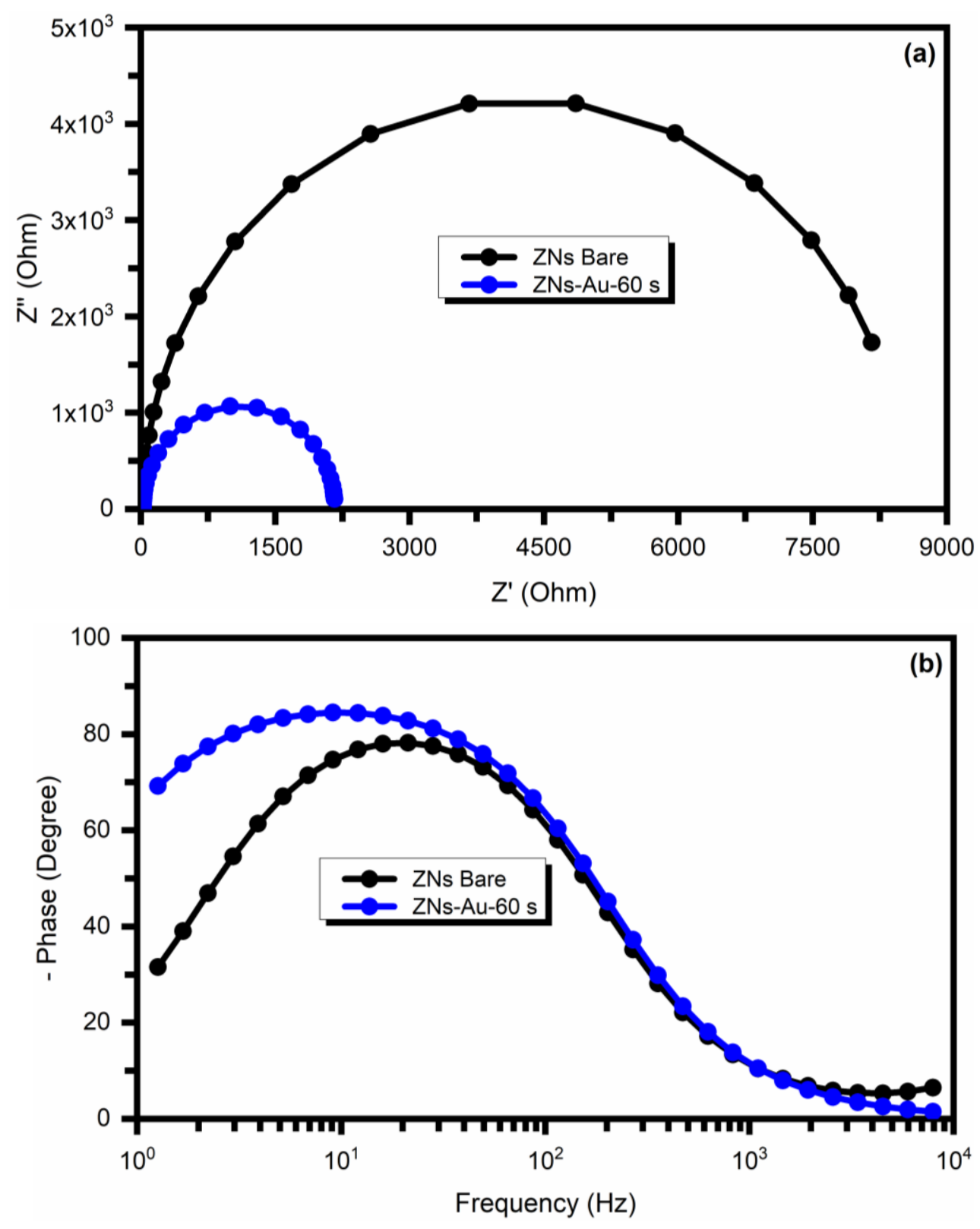
FIGURE 07

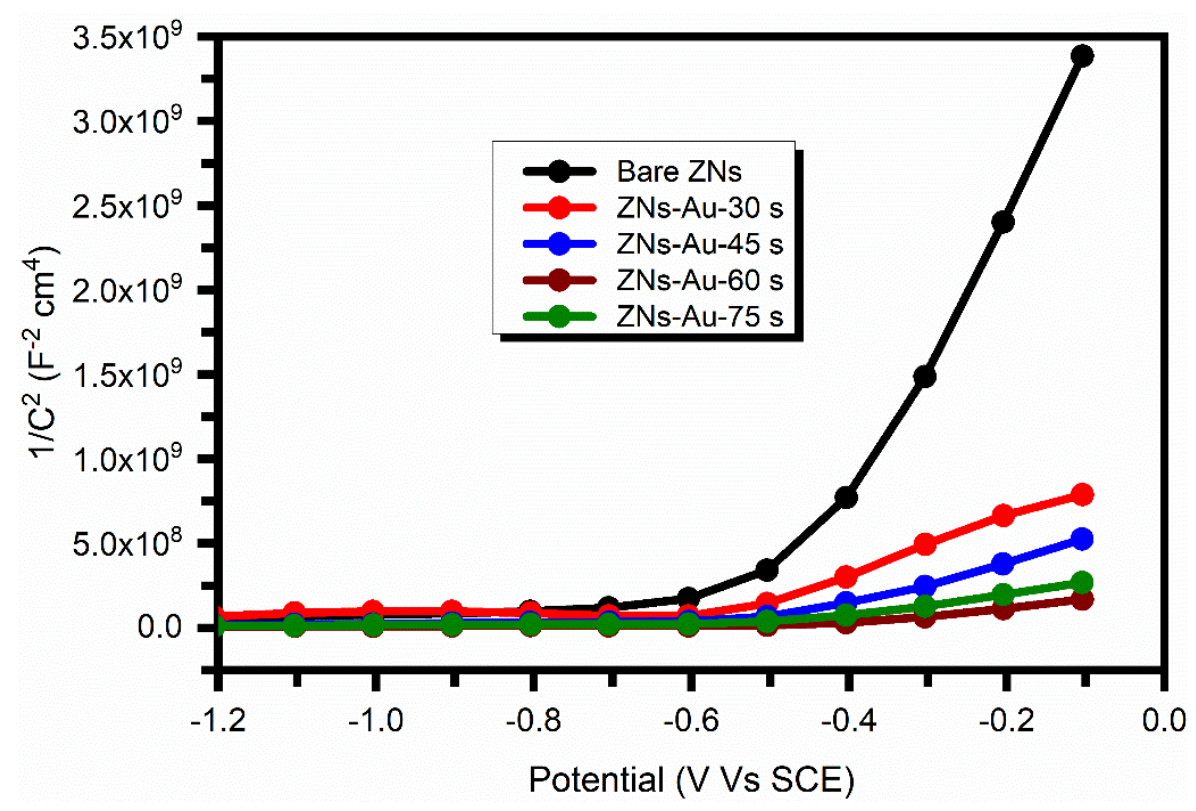


Figures

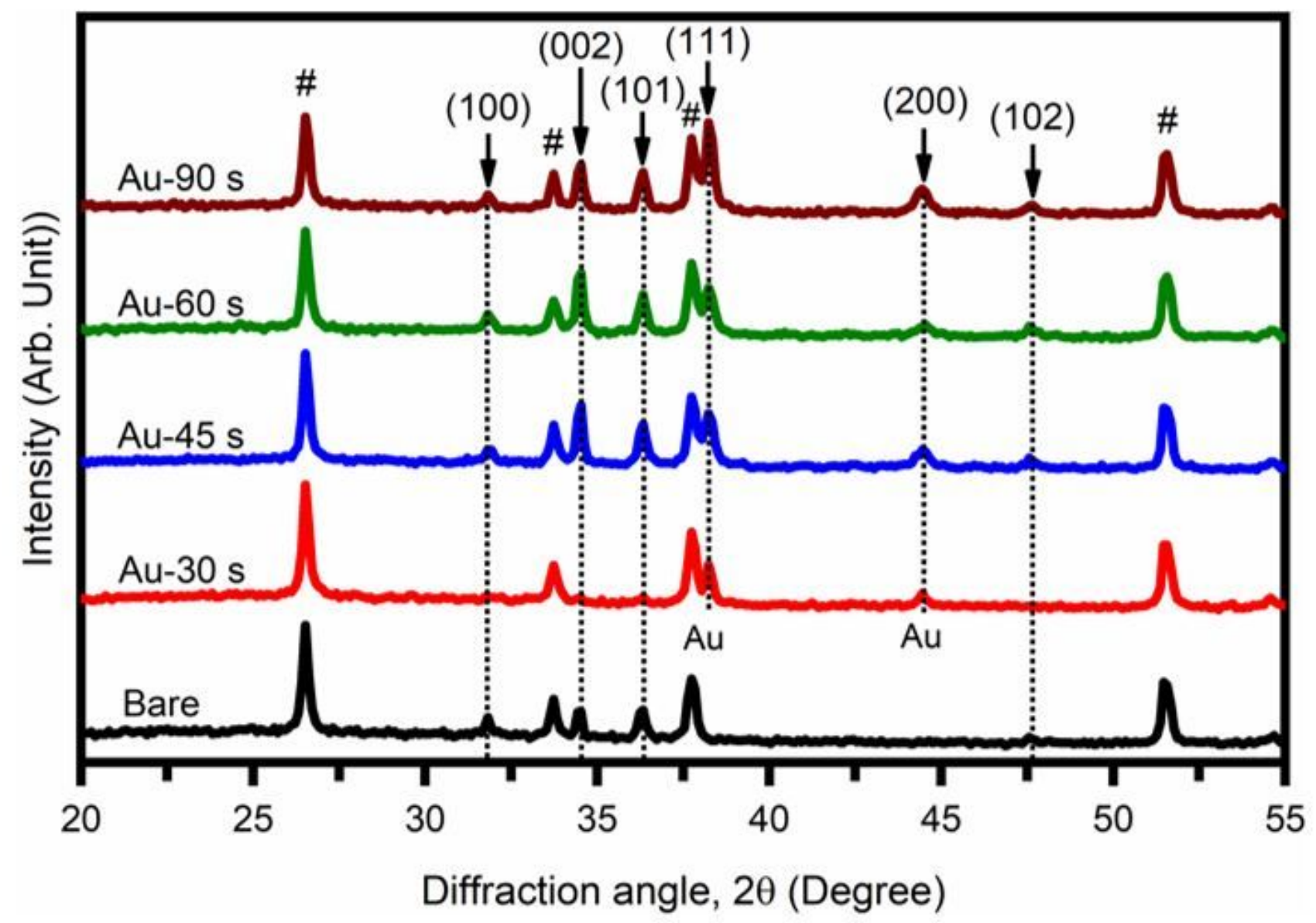

Figure 1

XRD spectra: ZnO nanorods (ZNs), ZNs-Au for different Au deposition durations. 

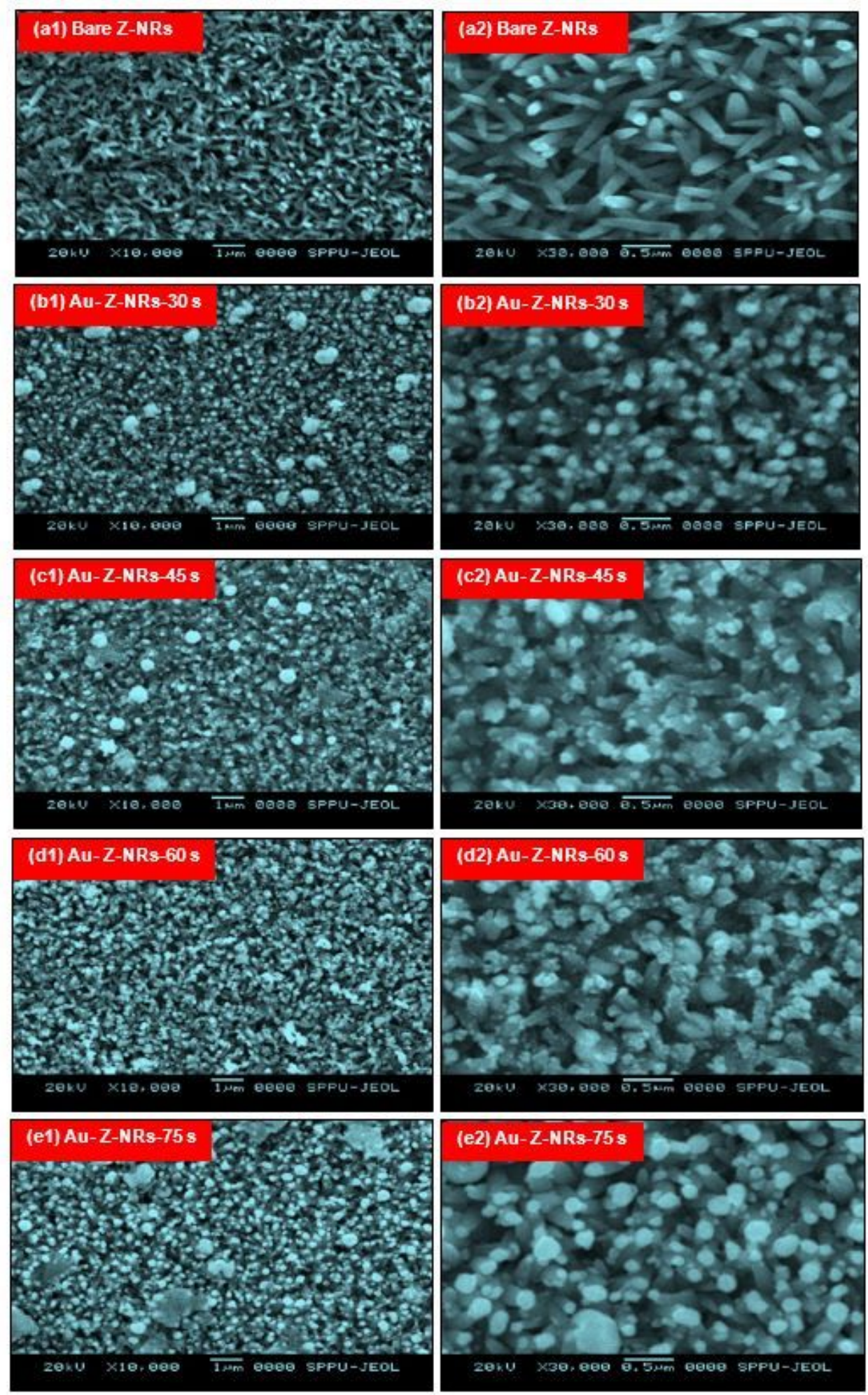

\section{Figure 2}

SEM images of synthesized photoanodes. a1) Bare ZNs, b1) ZNs-30 s, c1) ZNs-Au 45 s, d1) ZNs-Au 60 s, e1) ZNs-Au 75 s at low magnification (LM), a2) Bare ZNs, b2) ZNs-30 s, c2) Z-Ns-Au 45 s, d2) ZNs-Au 60 $\mathrm{s}, \mathrm{e} 2)$ ZNs-Au $75 \mathrm{~s}$ at high magnification (HM). 

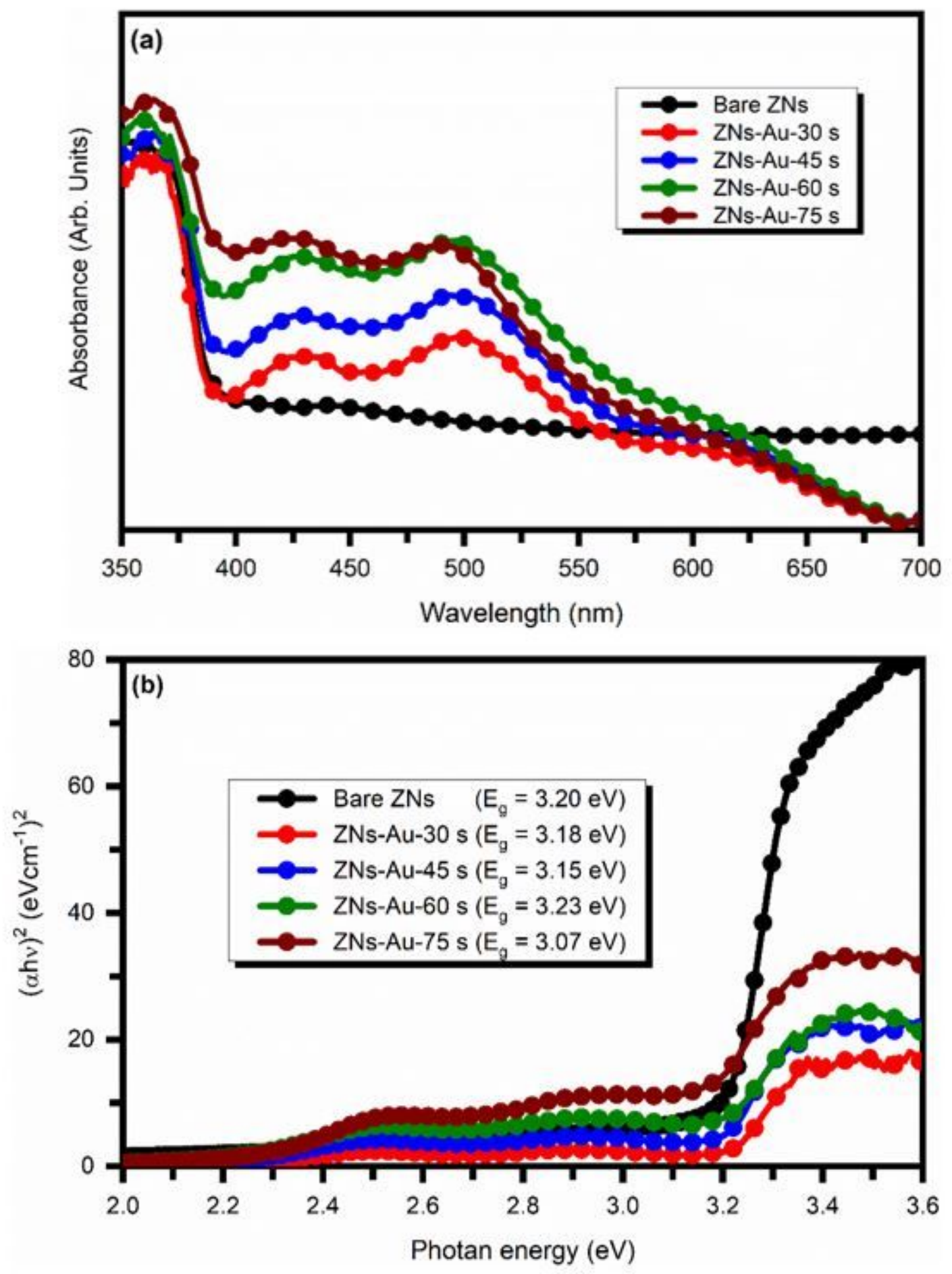

Figure 3

UV-Visible absorption spectra: for bare ZNs, ZNs-Au-30 s, ZNs-Au-45 s, ZNs-Au-60 s, and ZNs-Au-75 s. Inset shows the Tauc plot used to estimate the bandgap. 

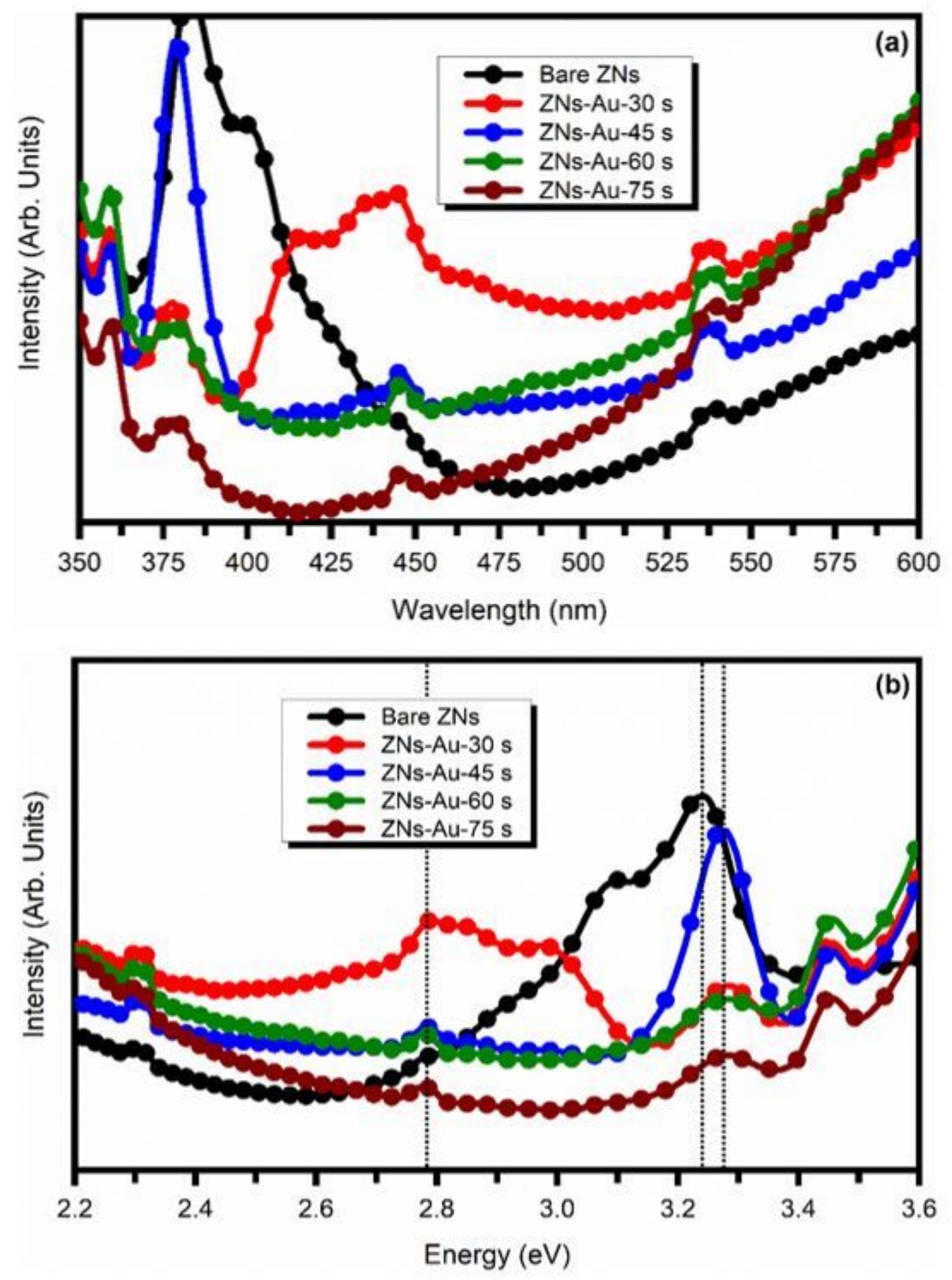

Figure 4

PL spectra: for bare ZNs, ZNs-Au-30 s, ZNs-Au-45 s, ZNs-Au-60 s, and ZNs-Au-75 s a) Emission spectra as a function of wavelength $b$ ) Emission spectra as a function of energy. 

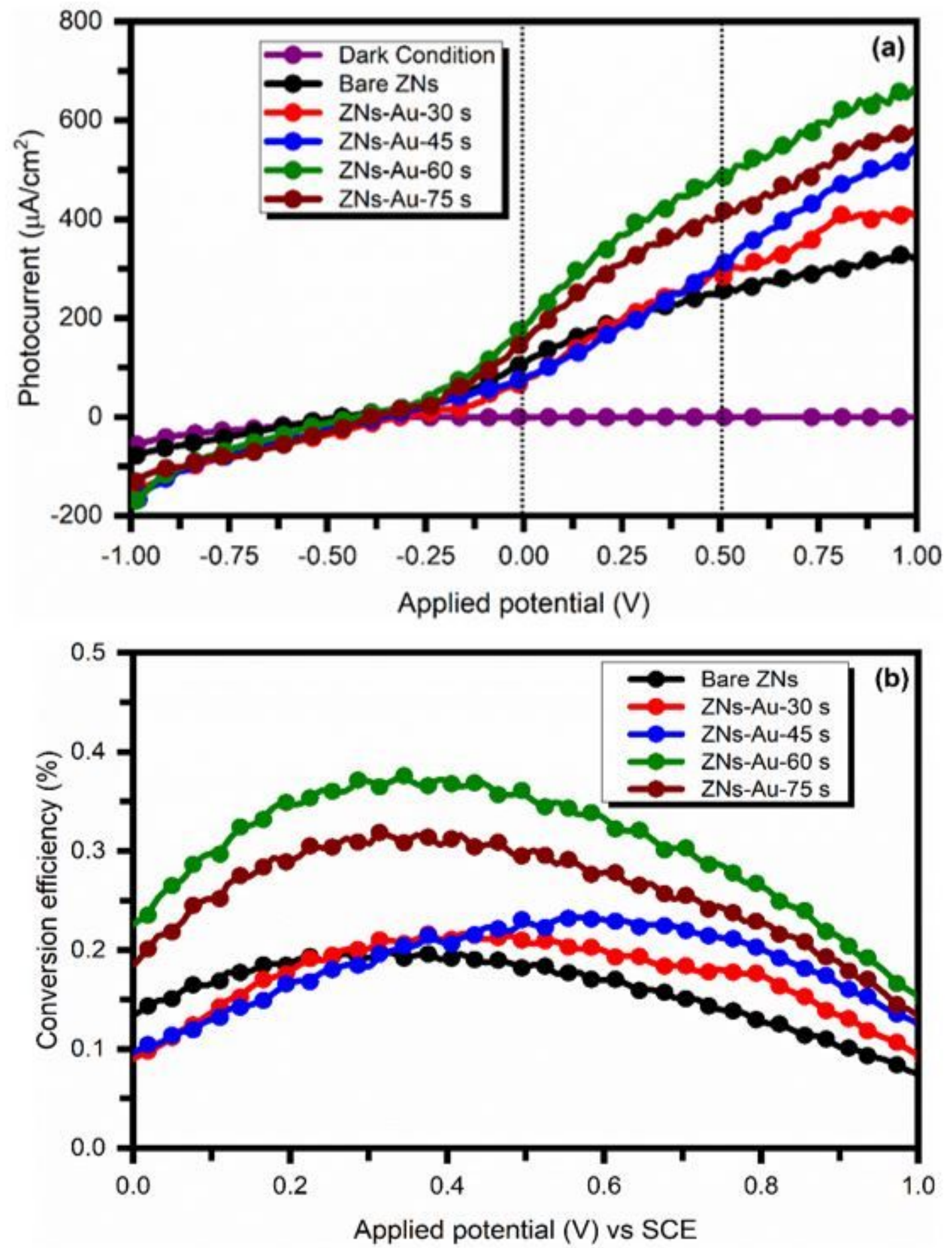

Figure 5

PEC characteristics of synthesized photoanodes a) J-V characteristics, b) photo-conversion efficiency. 

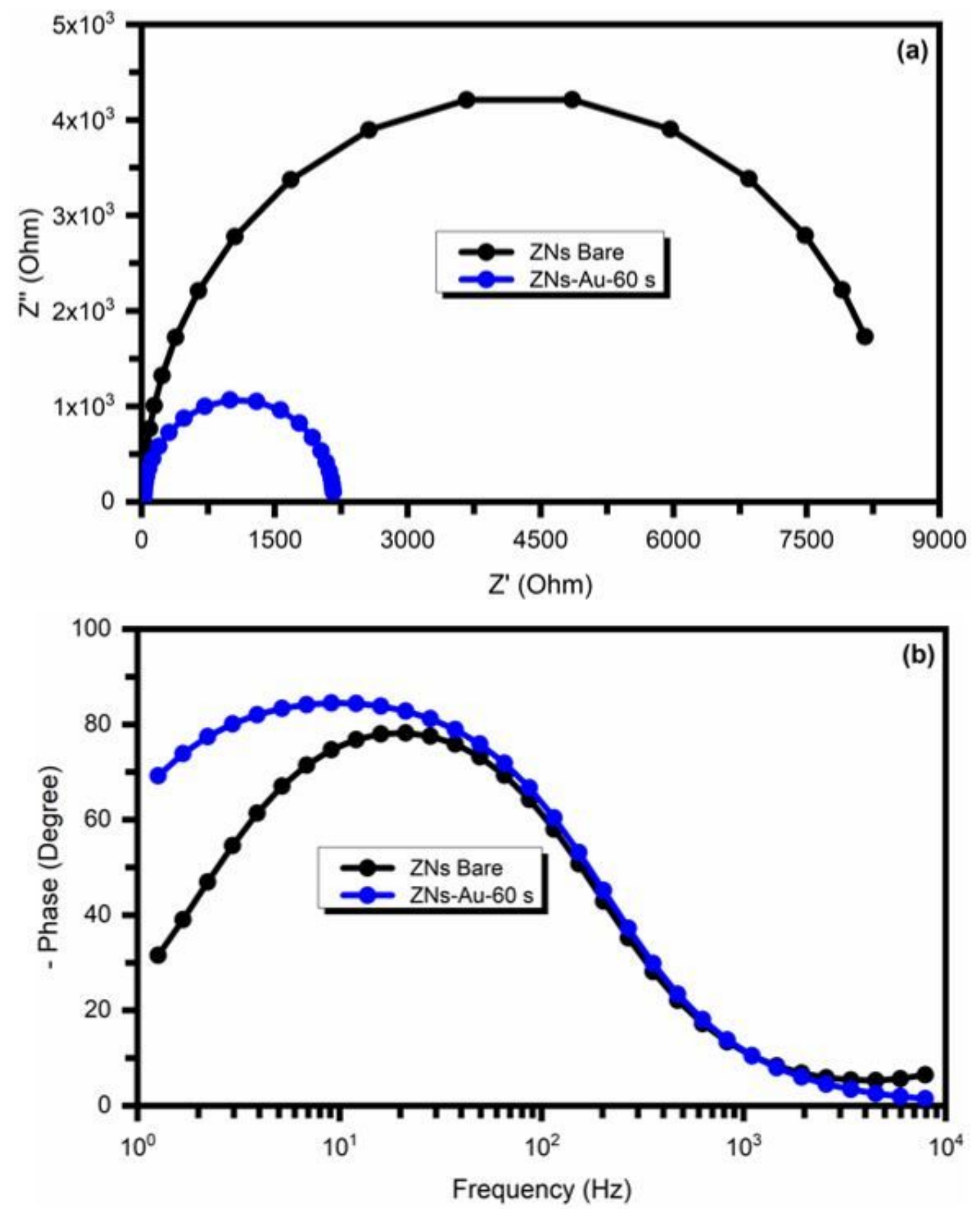

Figure 6

a) Nyquist plot for bare ZNs and ZNs-Au- 60 s photoanodes at $0.5 \mathrm{~V}$ under illumination in $0.5 \mathrm{M} \mathrm{Na} 2 \mathrm{SO} 4$, b) Bode plot of bare ZNs and ZNs-Au- $60 \mathrm{~s}$ at a bias potential of $0.5 \mathrm{~V}$ in light. 


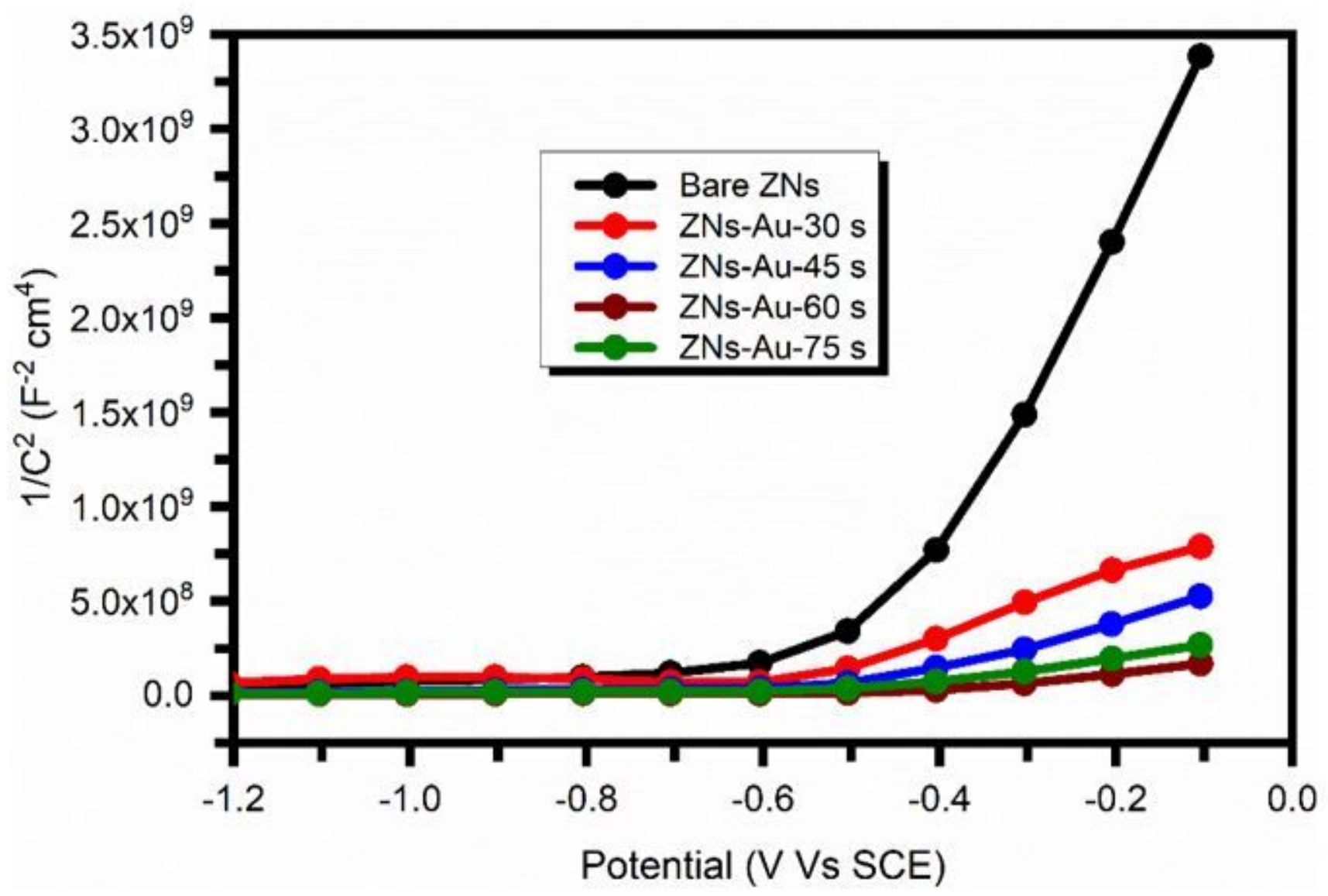

Figure 7

Mott-Schottky plots for ZNs-bare, ZNs-Au-30 s, ZNs-Au-45 s, ZNs-Au-60 s and ZNs-Au-75 s photoanodes. 